\title{
THE HYPERTONIC INFANT, THE CURATIVE ACTION OF ATROPIN ON CERTAIN OF ITS MANIFESTATIONS *
}

\author{
SIDNEY V. HAAS, M.D. \\ NEW YORK
}

The Hypertonic Infant is a definite clinical entity. It is character. ized by hypertonicity of all the skeletal muscles, as shown by the ability to raise the head and grasp objects even in the early days of life, and by general spasticity. The hollow viscera show increased activity of their smooth muscle fibers. This expresses itself in the form of spasm involving practically every part of the digestive tube, and, depending on the region, presents the symptom of colic, visible peristalsis, vomiting, constipation, or any combination of these. Accompanying these symptoms is marked psychic irritability, expressed by insomnia, general restlessness and crying. The hypertonic infant belongs to the spasmophilic group and presents the symptoms of Vagotonia. ${ }^{1}$

Its recognition is of importance in this, that while presenting symptoms in the main of disturbances of nutrition, food regulation alone does not correct the fault, whereas treatment by the drug atropin is followed by rapid subsidence of symptoms, the results being so prompt and regular as to constitute specific action. The tolerance for milk which is usually low in these infants is at once materially increased, so that a normal amount may be utilized-a condition quite opposed to that existing before the atropin was begun.

In the teaching of infant feeding stress has been laid on two factors: the food and the infant. The food has been studied from many angles, with the result that there is available an ample and satisfactory variety adaptable to most cases.

The infant, too, has been studied from many angles; but few serious attempts have been made to study the possibility of altering the infant's reaction toward food, when it is found impossible to adapt the food to it, despite the fact that idiosyncrasies have been noted and differentiated. Personal experience during the last few years has convinced me that in this direction lies a field which is full of promise in that ever diminishing group of difficult feeding cases. This paper deals with only one phase of the problem and will confine itself to the

* Submitted for publication March 4, 1918.

1. Eppinger and Hess: Vagotonia, Nervous and Mental Diseases, Monograph 20. Ed. 2, Nervous and Mental Disease Pub. Co., New York. 
consideration of one group whose adaptation to food would seem to have been accomplished through the adjustment of the vegetative nervous system.

To make clear the course of reasoning which has led to this conclusion, it is necessary to review very briefly a few points regarding the vegetative nervous system and its action.

The nervous system is made up of the sensori motor and the vegetative systems. The latter, with which only we are concerned, is subdivided into the sympathetic and autonomic. The sympathetic reacts to small amounts of epinephrin. The autonomic is all that portion not included in the sympathetic, includes the vagus, and reacts to very small amounts of acetylcholen. ${ }^{2}$ Under normal conditions these systems (the sympathetic and the autonomic) are in equilibrium, producing a "tonic innervation" of smooth muscles. Stimulation of one or the other system by hormones or other factors may produce contraction and spasm or paralysis.

Vagal stimulation, for instance, may cause turbulent gastric peristalsis which readily changes into retrograde peristalsis and may manifest itself in vomiting. Hence the benefit on cardiospasm and pylorospasm of atropin. If the motor vagus endings in the intestine are stimulated by pilocarpin or physostygmin, peristalsis is increased, and emptying of the bowel occurs. Under certain conditions, however, a tonic spasm of the sphincters may result, a hypertonicity with a spastic condition of the intestinal tract. ${ }^{1}$ The opposite effect, a relaxation and quieting of the intestines follows the use of atropin, which paralyzes the vagus. Owing to its close relation to the glands of internal secretion, the autonomic nervous system doubtless has a marked influence, not only on the pancreas and the thyroid gland, but also on the entire mechanism of metabolism. ${ }^{1}$

In the present imperfect state of our knowledge regarding the effects of food on the infant organism, it is not strange that a certain number of infants react in an abnormal way to the food introduced into the body. A normal healthy infant fed on the breast takes its food at intervals with apparent satisfaction, does not vomit, has normal stools, and sleeps most of the time between feedings, grows in size and increases in weight regularly. A normal, healthy infant fed artificially usually reacts in a similar manner.

A number of apparently normal, healthy infants fed on the breast, take their food with seeming satisfaction, grow and increase in weight, but are unhappy and restless, cry more or less constantly, sleep only at intervals for short periods of time, vomit and are constipated.

2. W. H. Gaskell: The Involuntary Nervous System, Monographs on Physiology, Edited by E. H. Starling. 
A much larger number of artificially fed than breast fed children react in this abnormal way and present this picture of unhappy, restless, sleepless, crying infancy. The cause of this state is to be sought in the manner in which the individual child reacts to its food. Where the fault lies is not readily discernible. Available laboratory methods by which the offending substance or combination of substances can be detected and removed from the diet are lacking. The correction by the usual clinical methods of experimentation with various foods, and their combinations, is a very slow one and one not always followed by success. It is to this group of cases, whether breast or artificially fed, that the present paper desires to call attention. The cases are fairly common, and extremely intractable unless treated in the manner to be referred to.

In this group are to be found: $(a)$ the colicky baby; $(b)$ the sleepless baby; $(c)$ the restless baby; $(d)$ the irritable baby which does not prosper on any food, although there is neither gastric nor intestinal indigestion; $(e)$ the baby suffering from pylorospasm accompanied by vomiting, usually projectile in type; $(f)$ the constipated baby.

Without exception these infants are of the spasmophilic diathesis; and usually with a neurotic ancestry.

That usual therapeutic procedures and rearrangement of diet are inadequate to relieve the symptoms is amply demonstrated by the fact that these cases drift from physician to physician to be relieved finally by time; that is, when the age is attained when solid food is used, or by operation when pyloric obstruction is diagnosticated.

The typical history is about as follows: Infant born at full term, entirely normal, fed at the breast, cries more than it should during the early days of life and is supposed to be having a great deal of colic. Beginning at once, or after several weeks, vomiting ensues; this is usually explosive but need not be of this type. The vomiting is not related to the taking of food and may occur after each nursing period, or only once or twice in twenty-four hours. The volume may be more than has been taken in at one nursing. Its very irregularity is characteristic. Because of this vomiting and irritability, changes are made in the diet, first, by modifying the breast feeding, in time, in quantity and by dilution. Usually this is ineffective. Artificial feeding is then begun and the condition becomes worse instead of better. The infant may gain normally, make only meager gains, or fail to gain at all. The infant is constipated, sleepless, and cries much more than it should.

These cases pass from hand to hand, changes are made in formula and method, but usually without much result. The diagnosis, where propulsive vomiting exists, is pylorospasm. And this is the correct diagnosis. Wherever the propulsive vomiting does not exist, the diagnosis is not made.

\section{SYMPTOMATCLOGY}

The sypmtomatology depends on when these children are first seen. Their weight is normal in the beginning; after some months they are 
below normal and frequently rhachitic. The infants without exception are hypertonic. They are able to raise their heads at birth, and grasp objects firmly. They can support themselves on their legs at the end of six or eight weeks if held up. The entire body may be raised by the head because of the rigidity. They are often referred to by the nurse and family as being very strong. An abdominal examination often reveals active gastric or intestinal peristalsis. One obtains the impression that they are unusually alert, they cry more or less constantly, rarely sleep except in short stretches, and are not happy babies. If this condition has not been corrected before five or six months, the emaciation may be marked.

Cases of this type present, in the order of their importance:

1. Vomiting, which, as before mentioned, is characteristically irregular, often with visible peristalsis.

2. Crying, which is more or less constant and violent.

3. Insomnia; this is usually a striking symptom, and with the crying creates a household state bordering on demoralization.

4. Constipation, resistant to ordinary laxative and dietetic treatment, and distinctly spastic in type, the stool being soft after it has once started.

5. Cold Extremities, with pallor, cyanosis and subnormal temperature. This is met with only occasionally.

6. Underweight; the degree depending on the age at which correct treatment is instituted-under 8 weeks, 1 to $11 / 2$ pounds; from 3 to 6 months, 3 to 4 pounds.

\section{TREATMENT}

Correct therapy shows results in this condition which are unusual in their regularity and in the rapidity with which they occur. Where indigestion exists, this of course must be improved by appropriate methods of feeding; as a rule, however, there is no indigestion and no change in diet is necessary.

By the administration of atropin in sufficient doses the entire picture changes in from forty-eight to seventy-two hours; in some cases even in twenty-four hours. The method of administering the atropin is in $1: 1,000$ solution, beginning with 1 drop in each bottle of food and increasing it in forty-eight hours, if there is no improvement, to 2 drops in each bottle, and later to three or four or more drops, if necessary, with an interval of forty-eight hours between change in ciosage.

If the diagnosis is correct, it will be found that the atropin controls the frequency of the vomiting. The child begins to sleep very much better and for longer periods; in its waking moments it is comfortable, and cries less or not at all. The vomiting usually ceases entirely or only occurs at rare intervals. Occasionally, one symptom of those enumerated persists long after the infant is in all other respects normal, and that is usually found to be due to some faulty detail in manage- 
ment. As a rule 1 or 2 drops of atropin at each feeding are enough, although frequently 3 or 4 drops or more are necessary to obtain a result. At intervals the atropin is reduced in amount, then discontinued. If there is no recurrence of symptoms, it is no longer required; if, however, the symptoms return, then the atropin must be resumed until repeated testing has shown it to be no longer necessary. This may require months; in some cases six months.

There have been no ill effects noticed from these large doses of atropin in infants, and it is a striking fact that infants a few months of age are able to take doses of atropin which would cause toxic symptome in the adult.

If atropin is used early and in sufficient dosage the number of cases of pylorospasm which finally reach the operating table as cases of hypertrophic stenosis will be reduced to an unimportant minimum.

It is not to be supposed that all infants who vomit, or cry, or do not sleep, or are constipated will respond to this treatment. On the contrary, if the cause is elsewhere than in the autonomic nervous system, there will be no result.

\section{DIAGNOSIS}

How is it possible to make a positive diagnosis? It is not possible to make a positive diagnosis by clinical methods, but one can make a probable diagnosis when the combination of vomiting, insomnia, crying, constipation and, sometimes, subnormal temperature exists in the presence of hypertonicity and in the absence of faulty feeding. Atropin, administered in full dose, will definitely establish the diagnosis.

The maximum dose of atropin used in twenty-four hours was $1 / 15$ grain. The maximum amount administered in a single dose was $1 / 16$ grain, where a mother at the Welfare Station at Lebanon Hospital misunderstood directions and gave a teaspoonful of a $1: 1,000$ solution instead of 1 drop, to a baby under 6 months. There were no ill effects.

The earliest symptom of the physiologic effects of atropin in infants is a flushing which gives them the appearance of having fever, which sometimes actually exists, but is usually not high, dilatation of the pupils and slight puffiness of the lids.

In two institutional infants not belonging to this group, atropin in doses of 1 or 2 drops of 1: 1,000 solution, after several doses produced hyperpyrexia, abdominal distention, flushing, restlessness, vomiting and diarrhea. This syndrome could be reproduced at will. Atropin in small doses paralyzes the efferent nerve endings which terminate in peripheral ganglia (for example, vagus) and in involuntary muscle. Atropin in large doses paralyzes the secretory fibers of probably all glands, including mucous glands, pancreas and liver; stops the movements and paralyzes the involuntary muscular fibers of the intestines so that they only contract feebly or not at all when directly irritated. ${ }^{3}$

3. Brunton: Pharmacology, Therapeutics and Materia Medica. Ed. 3, Lea Bros., Phila. 
Atropin by virtue of the greater than normal transmission of blood through the tissues increases metabolism and results in an increased elimination of waste products. ${ }^{4}$

Perhaps the description by a nurse in charge of one of these infants (Case 1), written at my request, will give a better picture than could be obtained in any other way.

\section{REPORT OF CASES}

CASE 1.-Referred by Dr. George L. Brodhead. Edward R., born March 8, 1917 ; normal delivery; mother of nervous, apprehensive type; baby weighed 7 pounds 8 ounces. Breast feeding was started on the fourth day. The baby

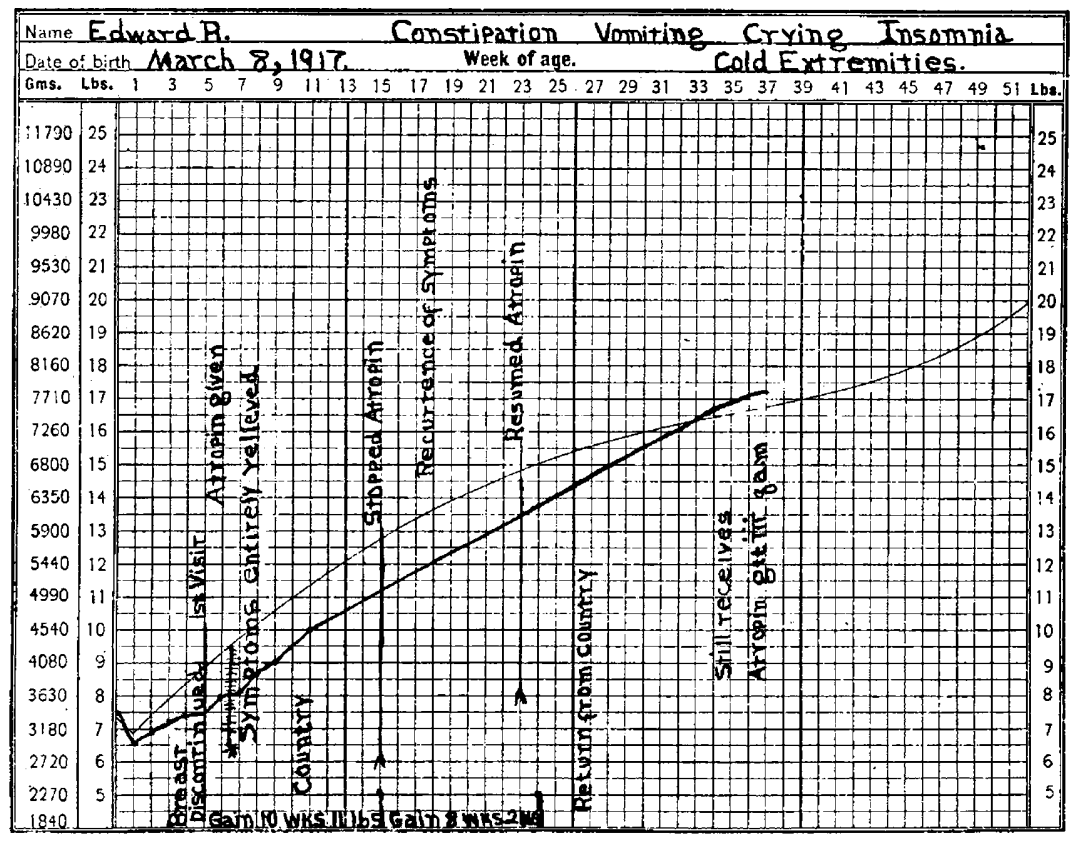

Chart 1 (Case 1).-Weight chart of Edward R.

obtained $11 / 2$ ounces on the fifth day every three hours. Meconium stools for three days. Castor oil, minims 10, produced a large mucous stool. The baby vomited mucus frequently for the first two and a half days. Lost 1.6 pounds by end of the first week. Temperature always between 98 and $98.2 \mathrm{~F}$.

Second Week: The infant cried one to two hours in twenty-four; obtained on an average 2 ounces at each nursing; stools normal; gained 6 ounces. Weight 6 pounds 14 ounces.

Third Week: Cried two to two and a half hours in twenty-four; received $21 / 2$ ounces at each nursing; stool normal; three to four daily passed with a large amount of flatus and considerable distress. Gain, 5 ounces. Weight 7 pounds 3 ounces. Mother up part of the day now ; very nervous and depressed (condition not caused by baby).

4. Bartholow: Materia Medica and Therapeutics. Ed. 11, Appleton and Co., New York. 
Fourth Week: Baby cried as though in pain three to four hours daily. (a) Given barley water, $1 / 2$ ounce before each three-hour nursing; $(b)$ given two feedings of 5-20 whole milk, with 1 ounce lactose in twenty-four hours. Regurgitated about $1 / 2$ ounce after three feedings daily. Vomited 1 to 4 ounces of sour curds after two feedings. Vomiting and regurgitation always occurred at time of stools and crying periods, which varied from day to day, most frequently occurring during the early morning or late afternoon. Weight increased 3 ounces. Weight 7 pounds 6 ounces.

Fifth Week: Breast nursing discontinued. $\cdot(c)$ Baby given 3 ounces 6-20 whole milk; regurgitated 1 ounce of each feeding; cries six hours daily, frequently holding breath; colic (?); no relief obtained by gastric lavage, which showed a clean, sweet stomach two hours after feeding, or colonic irrigations, which were almost impossible to give as the anus became tense and contracted, then relaxing; no stool for twenty-four hours after starting bottle feedings.

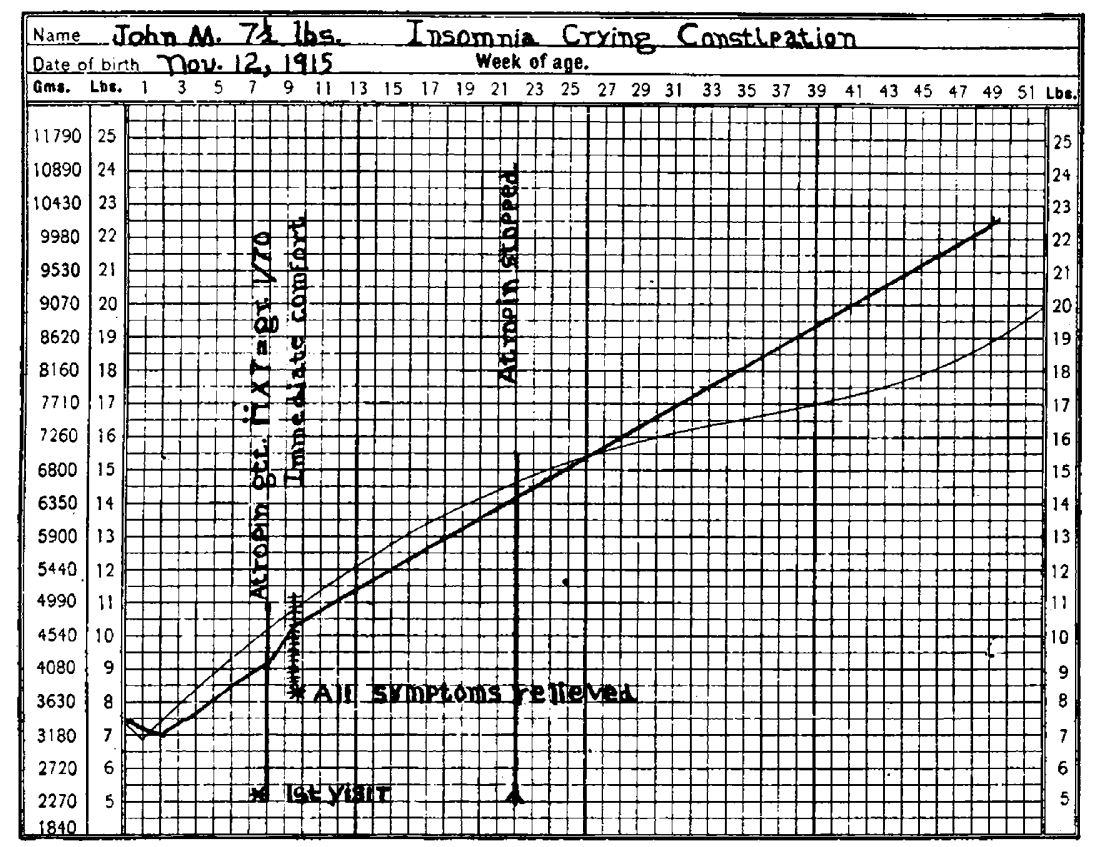

Chart 2 (Case 2).-Weight chart of John $M$.

Milk of magnesia, $1 / 2$ dram daily, produced one to two large, digested stools. Feedings reduced to $2 \frac{1}{2}$ and then to 2 ounces; lime water in each feeding, with no change in amount or frequency of vomiting or regurgitation. Gained 1 ounce. Weight 7 pounds 7 ounces.

Sixth Week: (First visit.) (d) Milk increased to 14 in 28 ounces; 3 ounces every two and a half hours; regurgitation and vomiting not increased by more frequent or larger feedings; crying periods the same; finger tips and lips sometimes blue after hard cry; hands clinched constantly; body tense.

(e) Dextro-maltose substituted for lactose; no improvement.

(f) Same formula continued with 1 minim atropin sulphate $1: 1,000$ in each two and a half hour feeding. After the third feeding a marked change was noticed in the baby's condition; first feeding retained; second and third retained for two hours; the baby then vomited about $1 / 2$ ounce of curds. It then passed a large normal stool; no laxative given. All feedings were retained on the 
following day; the baby practically stopped crying; entire body comfortably relaxed; gained 3 ounces in weight.

Thirty-two hours after the first dose the baby's body felt hot; temperature $100.4 \mathrm{~F}$.; face flushed, pulse 124. Atropin was omitted in the next feeding. Some puffiness under the eyes was noticed in the morning; temperature normal. Atropin 1:2,000, one-half drop, given during the day in each feeding, with some slight return of spasmodic crying and tension of body; atropin, $1: 1,000$ given in two succeeding feedings; condition relieved; gained 3 ounces. Quality and quantity of food unchanged. Atropin, 1:2,000 given in each feeding until the baby showed symptoms of returning tension and discomfort. Then $1: 1,000$ was given for several feedings, controlling the condition entirely. In five days the baby gained 9 ounces; temperature 98.6 to $99 \mathrm{~F}$. There was one large, digested stool daily, though still being passed with great effort and

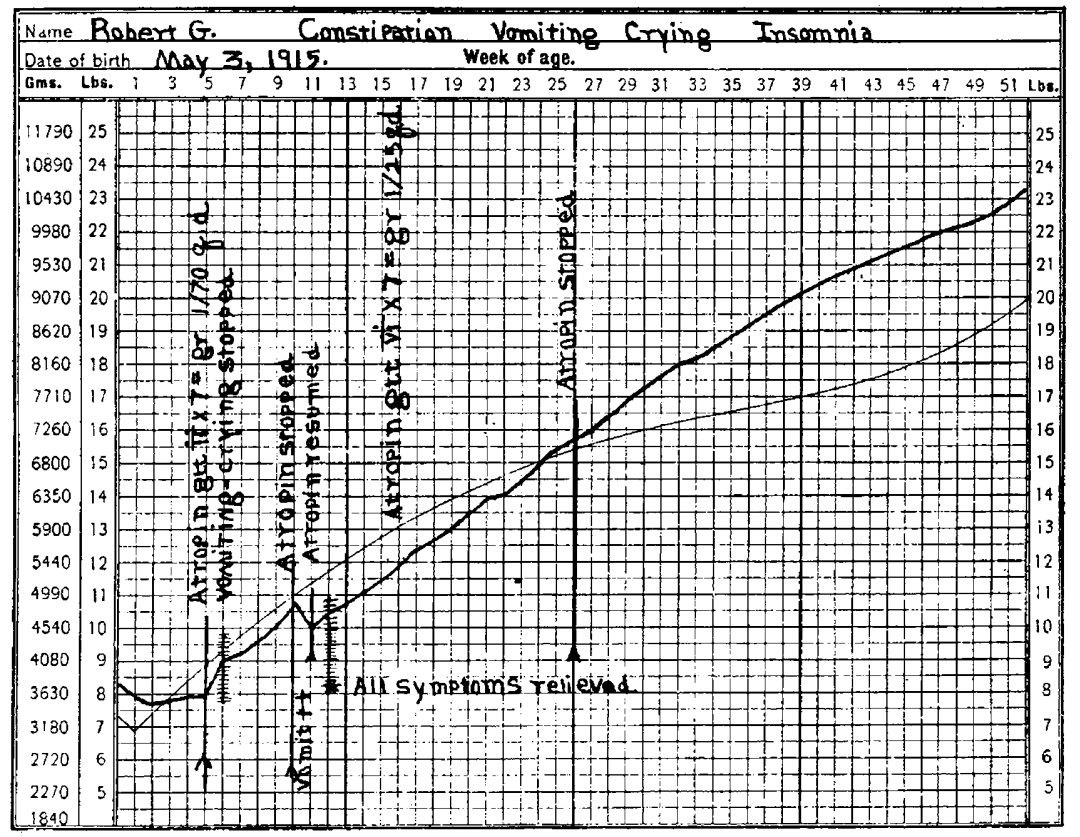

Chart 3 (Case 3).--Weight chart of Robert G.

some crying. The baby's whole expression changed; it looked comfortable; slept most of the time; extremities warm. From birth until starting the atropin treatment the baby's hands and feet were always cold unless especially covered with extra blankets and with hot water bottles in the crib.

Chart 2 (Case 2).-John M., born Nov. 12, 1915; weight 71/2 pounds. Complaint, insomnia, crying and constipation. Jan. 12, 1916, first visit; aged 2 months; weight $9 \frac{1}{2}$ pounds; first baby; labor normal.

Diet: (1) Breast milk; (2) milk, limewater, lactose, water; (3) condensed milk; (4) malt soup.

New Diet: Imperial granum, water, maltine, whole milk; 2 drops of atropin in each bottle. Ten days after new régimen was started there was a gain of 1 pound; general condition ++ .

Oct. 26,1916 , aged 11 months; weight $22 \frac{1}{2}$ pounds; stopped atropin at 5 months; stopped maltine at 9 months. The child did well after atropin was begun. 
Chart 3 (Case 3).-Robert G., born May 3, 1915; physical condition apparently good; weight $8 \frac{1}{2}$ pounds. Complaint, constipation, vomiting, crying and insomnia.

May 15, 1915, first visit, aged 12 days; weight 7 pounds 13 ounces.

Feeding: (1) Breast milk; (2) breast feeding and sodium citrate; (3) malt soup; (4) Schloss milk; (5) modified cow's milk. Paregoric was used for the crying and sleeplessness, without result.

June 15, 1915, atropin, 2 drops in each feeding; weight, 8.1 pounds.

June 22, 1915, weight 8.15 pounds; symptoms absent.

July 15,1915 , atropin stopped four days previously with return of symptoms.

Aug. 27, 1915, 4 months old; weight 11.14 pounds; occasional vomiting.

Dec. 4, 1915, 7 months old; weight 17.4 pounds; atropin stopped at sixth month; no symptoms.

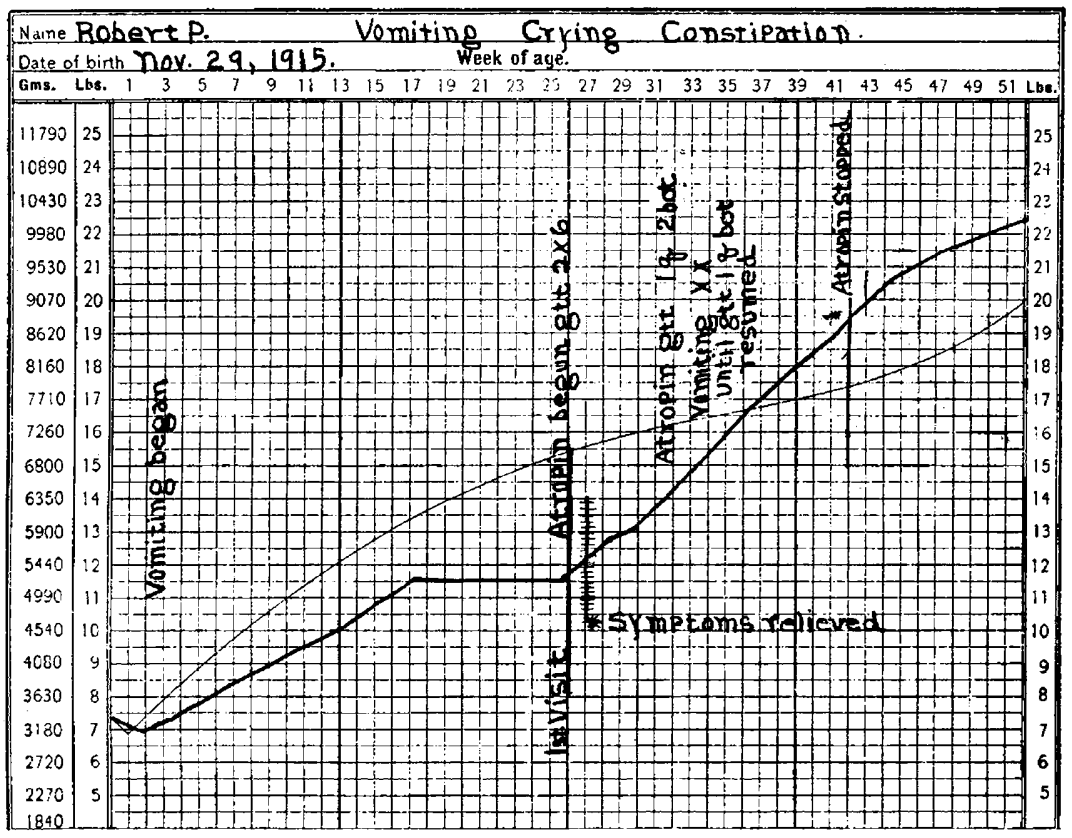

Chart 4 (Case 4).-Weight chart of Robert P.

Chart 4 (Case 4).-Robert P., born Nov. 1, 1915; weight 7.5 pounds; second child; labor normal. Complaint, vomiting, crying and constipation.

Feeding: (1) Breast and condensed milk two and a half months; slight gain; no vomiting; (2) top milk, granum, malt soup; curds, mucus and diarrhea; (3) barley, with skimmed milk; irregular gain; (4) granum, evaporated milk, lactose; (5) aqua cakes, water, lactose, milk. Began to vomit at three weeks (projectile), and has continued up to the present.

May 25, 1916, first visit; aged 6 months; weight 11.10 pounds; atropin, 2 drops in each bottle. New Diet: Granum $1 / 2$ ounce, maltine $1 / 2$ ounce, milk 20 ounces, water 16 ounces, divided into six bottles.

May 31, 1916, weight 12.3 pounds; symptoms absent.

July 24,1916 , occasional projectile vomiting; weight 16 pounds; 8 months old.

Several attempts to stop atropin resulted in a recurrence of symptoms within forty-eight hours. At the age of 25 months the weight was $291 / 2$ pounds; height 34 inches. 
Chart 5 (Case 5).-(Referred by Dr. A. W. Roff.) George H. S., born March 24, 1915; birth weight 9 pounds.

Complaint, insomnia, constipation, vomiting, crying and visible peristalsis. Second child; labor normal; present weight 8.15 pounds.

Feeding: (1) Breast three weeks; (2) condensed milk; (3) Horlick's malted milk; (4) granum; (5) modified milk; first visit (6) modified milk, fat $2 \frac{1}{2}$, protein $1 / 2$, granulated sugar 6 ; May 12, 1915, (7) modified milk, fat $13 / 4$, protein $13 / 4$, dextro-maltose $6 ; 3$ ounces every two and a half hours.

May 18, 1915, stool improved; vomiting severe; other symptoms not improved; weight 9.8 pounds; atropin started, 5 drops before each feeding.

May 19, 1915, no vomiting; quiet, but constipated; lips and throat dry; atropin reduced to 2 drops.

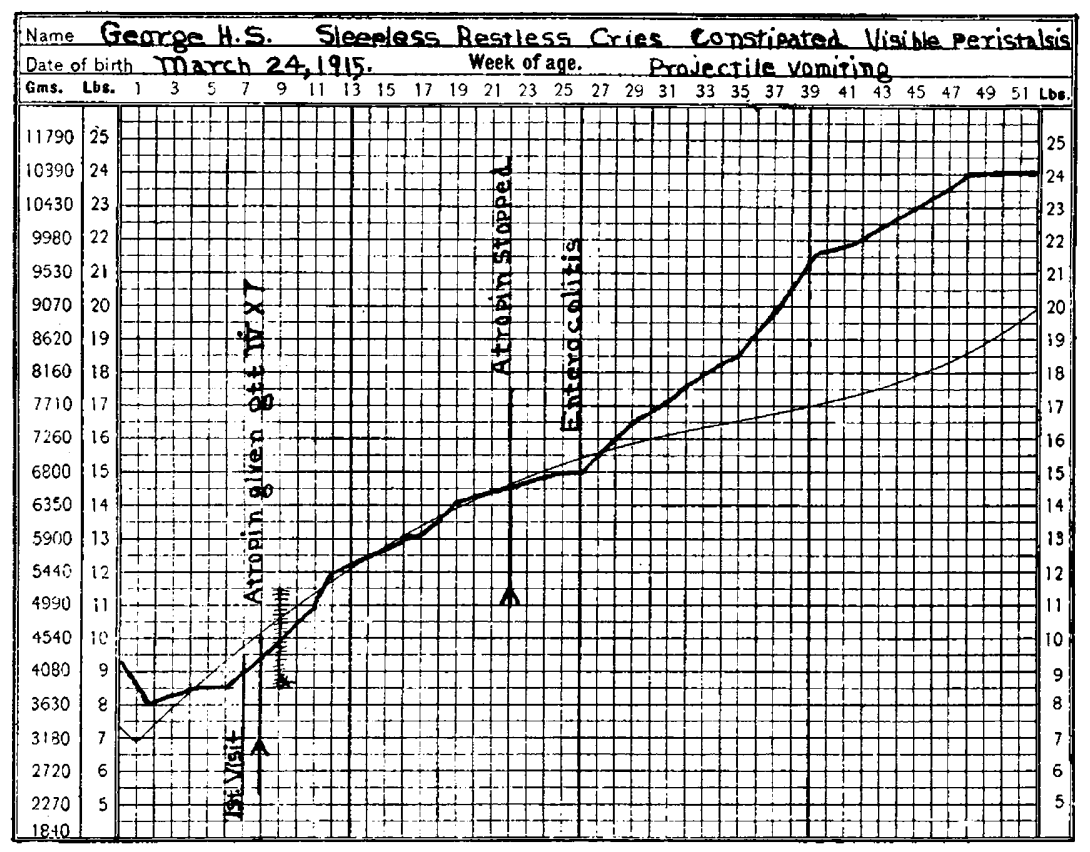

Chart 5 (Case 5).-Weight chart of George H. S.

June 26, 1915, appearance, good; slight sign of rickets; vomits infrequently ; sleep improved but cries and is constipated. Atropin stopped and paregoric, 12 drops, given in each feeding. This apparently had no effect. All symptoms returned. When atropin was used, it seemed to warm and quiet him.

July 23,1915 , weight $13 \frac{1}{2}$ pounds.

Formula: Milk 26 , barley water 8 , limewater 2 , dextro-maltose $2 \frac{1}{2} ; 61 / 2$ ounces, seven feedings. Received atropin, 4 drops at each feeding; could not get along on less; peristalsis visible at times; other symptoms practically absent, excepting those of rickets, which were slow in clearing up.

Atropin taken more or less constantly until the child was 1 year old.

Chart 6 (Case 6).-(Through courtesy of Dr. W. M. Stone.) Grace G., born May 19, 1916; second child; first died in labor; birth weight 5.8 pounds. Complaint, irritability, crying, vomiting and slight constipation.

Feeding: (1) Breast, two weeks; weight dropped to 4.10 pounds the first week; (2) barley water, limewater; present formula (3), milk 7, limewater 1, 


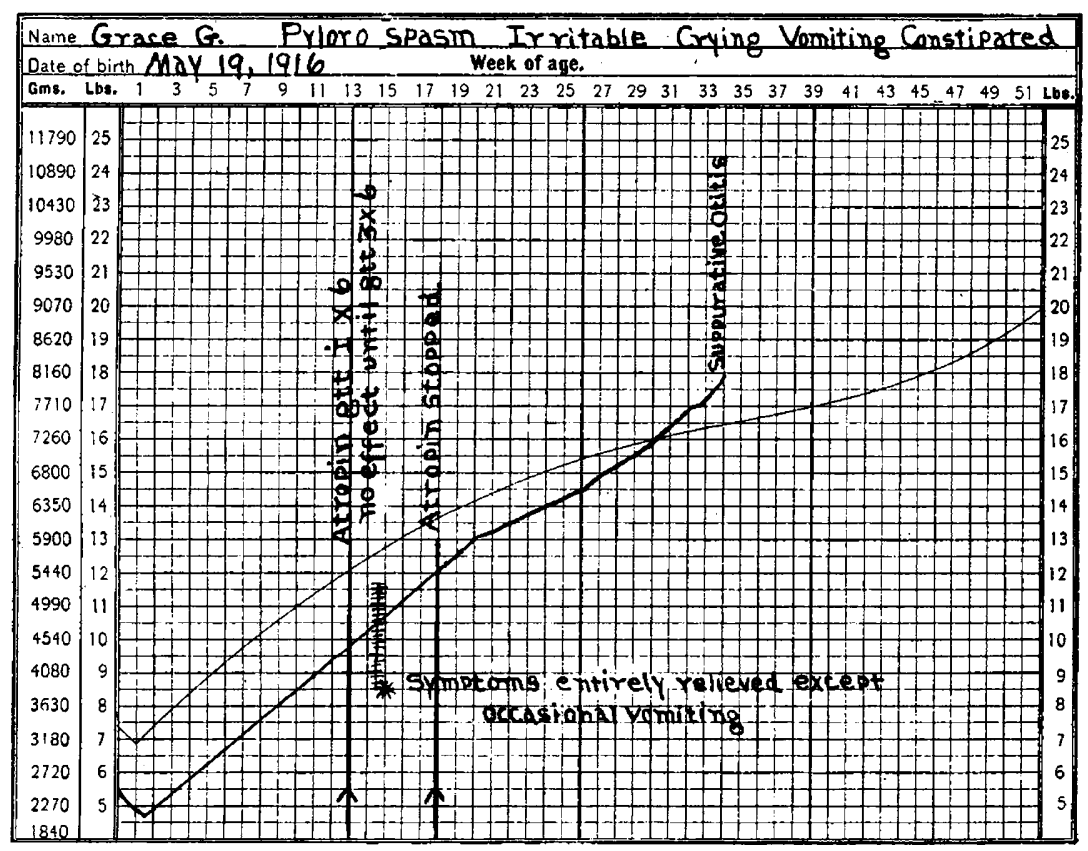

Chart 6 (Case 6).-Weight chart of Grace G.

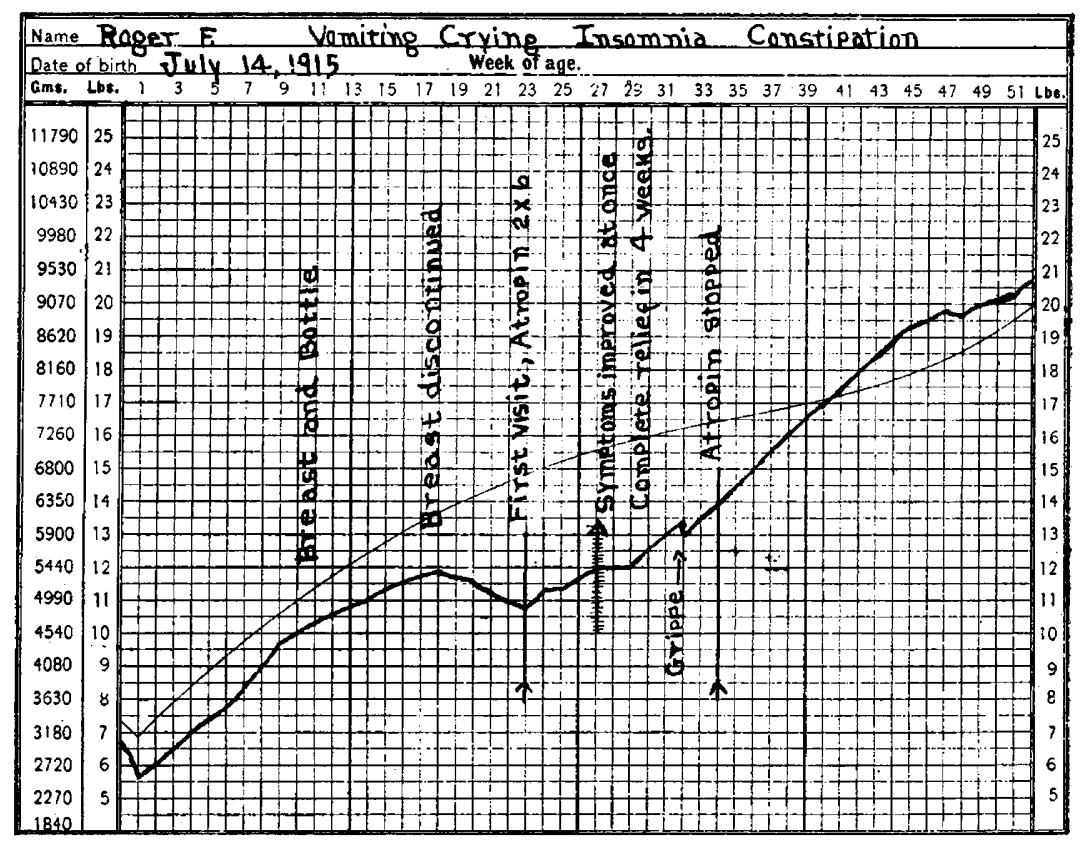

Chart 7 (Case 7).-Weight chart of Roger F. 
cane sugar 2, barley water $12 ; 4$ to 6 ounces every four hours; peptonized; peanut oil 1 drop fifteen minutes before feeding.

First visit, Aug. 16, 1916, weight 9.6 pounds; pale; abdomen shows peristalsis; stands with support; atropin, 1 drop in each feeding.

Aug. 25, 1916, symptoms relieved entirely, excepting the vomiting, which was not entirely eliminated; no effect from less than 3 drops of atropin solution.

Formula: Milk 12, dextro-maltose 2, limewater 1, barley water 10 .

Sept. 1, 1916, milk 15 ounces, dextro-maltose 2, limewater 1, barley water 9. Vomits about once a week; other symptoms absent.

Infant at present is peculiar and unsocial.

Chart 7 (Case 7).-(Referred by Dr. J. T. Simonson.) Roger F., born July 14, 1915; birth weight 6.10 pounds. Complaint, vomiting, crying, insomnia and constipation; no gain recently.

Previous Feeding: (1) Breast; (2) breast, barley water (3 months) ; (3) breast, top milk $91 / 2$, dextrinized barley water $10 \frac{1}{2}$ (fourth month); (4) top milk 8 ounces; barley water; (5) top milk 24 ounces; (6) skim milk; (7) milk, sugar, water; (8) condensed milk $1: 10 ;(9)$ top milk mixture peptonized; (10) malt soup; (11) protein milk.

Summary of Cases

\begin{tabular}{|c|c|c|c|c|c|c|c|c|c|c|c|c|}
\hline Case & Name & $\begin{array}{l}\text { Con- } \\
\text { stipa- } \\
\text { tion }\end{array}$ & $\begin{array}{c}\text { Vomit- } \\
\text { ing }\end{array}$ & $\begin{array}{c}\text { Insom- } \\
\text { nia }\end{array}$ & $\begin{array}{l}\text { Cry- } \\
\text { ing }\end{array}$ & $\begin{array}{l}\text { Peris- } \\
\text { talsis }\end{array}$ & $\begin{array}{l}\text { Los- } \\
\text { ing }\end{array}$ & $\begin{array}{c}\text { No } \\
\text { Gain }\end{array}$ & $\begin{array}{l}\text { Under } \\
\text { Wt., } \\
\text { Pounds }\end{array}$ & $\begin{array}{c}\text { Age } \\
\text { When } \\
\text { First } \\
\text { Seen }\end{array}$ & $\underset{\text { Begun }}{\text { Atropin }}$ & $\begin{array}{l}\text { Atropin } \\
\text { Stopped }\end{array}$ \\
\hline 1 & George S. .... & + & 4th wk. & $+?$ & + & + & .. & + & 1 & 7 wks. & $5 / 8 / 15$ & $8 / 24 / 15$ \\
\hline 2 & Robert G. .... & + & $2 d$ wk. & + & + & .. & + & .. & 1 & 5 wks. & $6 / 8 / 15$ & $11 / 5 / 15$ \\
\hline 3 & Roger F..... & $+?$ & Early & + & + & .. & $+t$ & .. & 4 & $51 / 2 \mathrm{mos}$. & $12 / 23 / 15$ & $3 / 18 / 16$ \\
\hline 4 & John M. ....... & + & ......... & + & + & .. & .. & Slow & 1 & 8 wks. & $1 / 12 / 16$ & $4 / 16 / 16$ \\
\hline 5 & Robert P. .... & + & 3d wk. & + & .. & + & .. & + & 4 & $6 \mathrm{mos}$. & $5 / 26 / 16$ & $10 / 9 / 16$ \\
\hline 6 & Grace G...... & + & 8th wk. & $+?$ & + & .. & .. & Slow & 3 & 13 wks. & $8 / 16 / 16$ & $10 / 22 / 16$ \\
\hline 8 & Edward R. ... & + & 4th wk. & + & + & + & .. & + & $11 / 2$ & $5 \mathrm{wks}$. & $5 / 24 / 17$ & $11 / 27 / 17$ \\
\hline
\end{tabular}

First visit, Dec. 23, 1915, aged 51/2 months; weight 11 pounds ; marked rickets. Prescribed full milk, 20 ounces, granum $1 / 2$ ounce, maltine $1 / 2$ ounce, water 16 ounces, 9 ounces every four hours; atropin, 2 drops in each feeding.

Dec. 28, 1915, appearance good; sleeps well; is comfortable; some spitting; constipation.

Jan. 28, 1916, symptoms entirely relieved; only slight gain. Weight 9.12 pounds. Was now put on a straight milk formula: milk 30, lactose 1 , barley water 5 , limewater 2 .

Feb. 5, 1916, weight 12.10 pounds.

March 28,1916 , aged $81 / 2$ months; weight 15.8 pounds; no symptoms ; atropin stopped ten days previously.

\section{SUMMARY}

The hypertonic infant shows a tendency to rigidity, overaction of involuntary muscles and soon after birth develops signs of physical and psychic irritation, presenting the syndrome (physical) of vomiting, often visible peristalsis, constipation and imperfect nutrition; (psychic) of general irritability, insomnia and crying. 
The etiologic factor of this state would appear to be a hyperexcitability of the autonomic nervous system.

Although apparently a feeding problem, changes in method and character of feeding does not correct the condition.

Atropin in doses of 1 drop or more of a $1: 1,000$ solution with each feeding usually relieves the condition at once and apparently increases the infant's tolerance for milk.

Atropin in these cases may be used in large doses without danger. Investigation along these lines may reveal the etiology of hypertrophic pyloric stenosis.

666 West End Avenue. 